Samo PAVLIN*

\title{
PANDEMIJA COVIDA-19 KOT POVOD ZA SPREMEMBE RAZVOJA KOMPETENC V SVETU DELA IN VISOKEM ŠOLSTVU**
}

Povzetek. V članku smo najprej pojasnili vpliv pandemije na poklicne spremembe. V naslednjem koraku smo opisali, kako pandemija vpliva na razvoj kompetenc $v$ visokošolskem sistemu: posredno prek poklicnih sprememb in neposredno prek načinov učenja in poučevanja. Še posebej smo se osredotočili na problematiko selitve večjega dela pedagoškega procesa na splet, na spremembe, povezane s preverjanjem znanja, zaplete okoli mednarodne mobilnosti in na omejitve pri raziskovanju in pridobivanju relevantnih delovnih izkušenj. Pri tem smo predvidevali, da v srednjeročnem obdobju visoko šolstvo pri vprašanjih razvoja kompetenc ne bo reagiralo strateško, temveč bo iskalo kratkoročne rešitve za ohranitev izvedbe pedagoškega procesa. Na podlagi analize literature smo identificirali naslednje razvojne scenarije sprememb v visokošolskem sistemu: "digitalizacija"visokega šolstva, intenzivno prilagajanje programov trgu dela, vpeljava radikalnih sprememb, posel kot običajno in hibridni model.

Ključni pojmi: trg dela, visoko šolstvo, univerza, visokošolski diplomanti, zaposljivost, pandemija, kompetence

\section{Uvod}

Članek končujem ob koncu tretjega vala pandemije Covida-19. Pandemija je močno vplivala na različne aspekte družbenega delovanja, vrednote in navade. Številne negativne psihološke posledice, kot so anksioznost, apatičnost, depresija in slabše psihofizično stanje, so zaznamovale tako procese izobraževanja kot tudi trg dela (Le in Nguyen, 2021). Zaradi fizične in socialne distance, nošenja obraznih mask ter zaustavitve socialnega življenja se spreminja družbena interakcija - še posebej sta otežena neverbalna komunikacija in izražanje čustev. Segmentacija trga dela dobiva

* Dr. Samo Pavlin, redni profesor, Fakulteta za družbene vede, Univerza v Ljubljani, Slovenija.

** Izvirni znanstveni članek. DOI: 10.51936/tip.58.3.806-826 
nov zalet. Izobraževalni sistem še ni imel časa zajeti sape in pripraviti poglobljenih izhodnih strategij. Jasno postaja, da se problematika razvoja kompetenc srečuje z novimi izzivi. V tem kontekstu lahko v treh korakih opišemo namen članka. V prvem koraku je namen članka pojasniti vpliv pandemije na poklicne spremembe. $V$ drugem koraku bomo opisali, kako pandemija vpliva na razvoj kompetenc $v$ visokošolskem sistemu: posredno prek poklicnih sprememb in neposredno prek načinov učenja in poučevanja. Na podlagi teh izhodišč si zastavljamo naslednje temeljno raziskovalno vprašanje: "Kakšni so glede na potek pandemije možni scenariji razvoja kompetenc $v$ visokem šolstvu?"

Ponovimo naj, da koncept kompetenc v številnih razpravah povezuje sfero izobraževanja s trgom dela. Kompetence razumemo kot sposobnost uporabe znanja v določeni socialni situaciji. Glede na pretekle raziskave lahko ugotovimo, da na razvoj kompetenc vplivajo zelo različni dejavniki, kot so socialni kapital in izobrazba staršev, zgodovina izobraževanja in še posebej načini učenja in poučevanja, relevantnost delovnih in zaposlitvenih izkušenj, tranzicija na trg dela, pričakovanja delodajalcev po kompetencah, kvaliteta zaposlitev in še bi lahko naštevali (npr. Allen et al., 2011). Izobraževalni sistem je torej samo eden od dejavnikov, ki vpliva na razvoj kompetenc. V času pandemije ni znano, kako se bo v naslednjem obdobju spreminjala njegova vloga pri zaposlovanju mladih diplomantov. Trenutno večjo skrb predstavlja problematika nemotene izvedbe izobraževanja.

Že pred začetkom pandemije smo se v Evropi kot tudi na globalni ravni spraševali, ali visokošolske institucije namenijo razvoju kompetenc in zaposljivosti mladih dovolj pozornosti. Med pandemijo je problem postal večplasten. Trg dela in poklicne skupine trenutno namreč močno segmentirajo. Kot bomo pokazali v nadaljevanju, poleg obstoječe delitve na bolj in manj kvalitetne zaposlitve stopa v ospredje delitev na »nujne» (npr. zdravstvo) in "ostale" poklice (npr. umetnost). Tako je prehod iz izobraževanja na trg dela postal v življenju mladih ljudi še bolj negotova prelomnica, kot je bil pred pandemijo, odgovor na vprašanje, kako naj visoko šolstvo kompetence mladih prilagodi trgu dela, pa še bolj oddaljen. Zelo je odvisen od nadaljnjih, s pandemijo povezanih dogodkov v naslednjih mesecih in letih.

Metodologija tega konceptualnega članka je v prvem koraku zasnovana na eksploratornem, sistematičnem in predvsem integrativnem pregledu (zlasti) novejše literature. Cilj takega pristopa je predvsem generirati novo znanje (Torraco, 2016): v našem primeru smo pregledali in kritično ovrednotili in sintetizirali aktualne raziskave in znanstvene članke s področja trga dela in visokega šolstva $v$ obdobju pandemije. Na ta način smo identificirali ključne »bele lise«, ki smo jih dopolnili z novimi idejami, koncepti in poantami. V drugem koraku smo na podlagi prejšnjega izdelali razvojne scenarije. Metoda izdelave scenarijev v našem primeru na podlagi sistemskega 
razmišljanja kombinira obstoječa dejstva s področja izobraževanja in zaposlovanja ter jih povezuje s področji demografije, gospodarstva, politik in javnega zdravstva. Kljub kritikam o arbitrarnosti metode gre za pomemben pristop, saj temelji na poglobljenem in kreativnem razmišljanju o prihodnosti, z namenom razvoja več možnih rešitev, in ne le tiste, za katero najbolj verjamemo, da se bo zgodila (Bishop et al., 2007: 5).

\section{Spremembe, ki jih pandemija prinaša na trg dela in za delovna mesta}

\section{Nove oblike segmentacije trga dela, fizično distanciranje in delo na daljavo}

Pandemija je trg dela zaznamovala na različne načine. Uvedla je delitev na nujne poklice in ostale (Powell, 2020). Nujni poklici se še posebej nanašajo na področje zdravstva, socialnega dela, prodaje nujnih dobrin v trgovini na drobno (prehrana, farmacija) in transporta. Kot navaja Eurofoundovo poročilo, se je $\mathrm{v}$ času pandemije občutno znižala stopnja zaposlenosti $\mathrm{v}$ segmentu tistih, ki so zaposleni po pogodbah za določeni čas (Eurofound, 2021). Poročilo navaja, da so odpuščanja in ostala omejevanja zaposlovanja najbolj prizadela mlade in ženske v sektorjih, kot so turizem, prehrana, umetnost in zabava. Del zaposlenih z večjo socialno varnostjo je bil deležen državne podpore, del tistih, ki so opravljali priložnostna dela, ali pa so bili zaposleni prek agencij za posredovanje dela, teh nadomestil ni dobil (prav tam). Razvoj smernic, povezanih z okrevanjem trga dela glede na $\mathrm{ILO}^{1}$ in OECD $^{2}$ (ILO-OECD, 2020), kaže, da se bo trg dela v naslednjem obdobju srečeval z različnimi ukrepi za preprečevanje širjenja virusa, težavami nastajanja novih delovnih mest, izpadom dohodka, preprekami pri iskanju novih zaposlitev, slabšanjem pogojev delovnega življenja, šibitvijo socialnega dialoga, porastom dela na črno, omejitvami vseživljenjskega učenja ter težavami prehoda mladih na trg dela. Negotovost o tem, kako naj (visokošolski) izobraževalni sistem pripravi mlade na zaposlitveno kariero, se bo v takih okoliščinah povečala.

Poleg omenjenega je pandemija zelo spremenila kontekst izvajanja delovnih nalog mnogih poklicev. »Digitalni vidiki« fleksibilizacije dela so postali temeljni izziv organizacije dela in zaposlovanja: že v drugem valu leta 2020 je več kot 50 odstotkov zaposlenih delalo občasno ali trajno z oddaljenim dostopom (Eurofound, 2021: 1). Ob tem so se mnogi poklici začasno ali trajno »digitalno transformirali« (med obema skupinama obstaja pomembna

1 Kratica za Mednarodno organizacijo dela: International Labour Organisation.

2 Kratica za Organizacijo za ekonomsko sodelovanje in razvoj: Organisation for Economic Co-operation and Development. 
razlika, ki pa v času pisanja članka ni povsem jasna!). To odpira izhodišča za "nove« pojavne oblike poklicne segmentacije (npr. privilegij dela od doma). Med številnimi opredelitvami tega pojava velja omeniti Alamovo (2020: 602-603), ki je poklice v luči aktualnih dogodkov razčlenil v tri skupine: a) rutinske poklice, primerne za delo od doma, katerih delo je moč jasno razdeliti med posamezne izvajalce, in ne zahtevajo interakcije (npr. vnašanje in procesiranje podatkov); b) poklice, ki zahtevajo kvalifikacije za tesno sodelovanje med zaposlenimi in koordinacijo aktivnosti, vendar je personalne vložke mogoče identificirati (npr. različne oblike projektnega dela, produktni dizajn in marketing); c) poklice, ki temeljijo na stalni interakciji med posamezniki s telesnim kontaktom ter telesno govorico. Poklice, ki jih je moč delno ali v celoti opravljati na daljavo, lahko sicer razvrstimo v tri skupine (Mlinar, 2003; Messenger in Gschwind, 2016): a) teledelo, ki ga je moč opravljati doma s pomočjo informacijsko-komunikacijske tehnologije; b) teledelo, ki se ga opravlja iz oddaljenih pisarn ali drugih dislociranih enot delodajalca (npr. laboratoriji, podružnične pisarne, klicni centri ...); c) mobilno delo, ki ni vezano prostorsko na določeno lokacijo in ga je moč opravljati v prostorih delodajalca, strank ali od doma. Delo na daljavo sicer prinaša nekatere prednosti, kot so zmanjševanje stroškov, prihranek časa, boljše možnosti usklajevanja delovnega in družinskega življenja ter manjšo možnost virusnih okužb. Vendar pa - skladno z antropološko-historičnim pogledom - izoliranost odtujuje delo zaposlenim in preprečuje doseganje dobrih delovnih rezultatov.

Spremembe pravil fizičnega distanciranja torej predstavljajo za večino poklicnih skupin in organizacij velike izzive, saj se dotaknejo bistva organizacije dela, načrtovanja, vodenja in kontrole. Spremenjena je samo vloga vodij. Ti so poleg rednih zadolžitev vedno bolj vključeni v specifike rokovanja s tehnologijo, skrbijo za čustveno stabilnost in blagostanje zaposlenih, vodijo alternativne oblike komunikacije, se povezujejo s strateškimi procesi in zagotavljanjem finančne stabilnosti ter pogosto tudi osmišljajo spremenjene okoliščine delovanja (Dirani et al., 2020). S tem so povezane spremembe pri upravljanju človeških virov: zaposlovanje, usposabljanje in razvoj, spreminjanje standardov učinkovitosti ter elementi motivacije. V spremenjenih okoliščinah številnim zaposlenim pogosto ni povsem jasno, kaj se od njih pričakuje: delo prilagajajo na eni strani strogim pravilom in na drugi procesom improvizacije. Koordinacija delovnih aktivnosti in komunikacija sta pogosto močno oteženi, ravno tako prenos tihega znanja, ki v velikem obsegu zahteva fizično navzočnost. Spontana srečanja v organizaciji, zaradi katerih delovni procesi potekajo tako, kot potekajo, so otežena ali do njih ne prihaja. Pri številnih organizacijah lahko zaznamo redukcijo fizičnih stikov in selitev manj nujnih aktivnosti na orodja za oddaljeni dostop, kot sta recimo Microsoft Teams in Zoom. 
Vpliv fizičnega distanciranja in dela na daljavo na uspešnost izvedbe nalog je zelo odvisen od specifik poklicne skupine. Pri lektorjih, na primer, kjer fizična navzočnost za opravljanje dela ni potrebna, se je raven kvalitete rezultatov dela med pandemijo malo spremenila. Pri učiteljih je drugače: med prvim valom pandemije so se pojavila številna opozorila o instrumentalizaciji učnih procesov in pasivizaciji učencev. Delo drugih poklicev, kot so na primer poklici na področju kulture in organizacije množičnih dogodkov, je v celoti zastalo. Zaradi tega je v številnih sektorjih prišlo do slabljenja poklicnih in organizacijskih identitet. Slednje pomembno vpliva na uspešnost izvajanja delovnih nalog ter celotno logiko upravljanja poklicnega znanja (Pavlin et al., 2011). Učno in delovno okolje namreč predstavljata pomemben gradnik poklicne socializacije, logike prevzemanja vrednot, norm in vedenjskih obrazcev. Dinamika uvajanja oddaljenega dela torej ne vpliva neposredno samo na način, kako so delovni rezultati doseženi, temveč tudi na subjektivne in objektivne komponente "profesionalnosti« opravljanja dela. To lahko opazujemo na ravneh posameznika, organizacije in poklicne skupine. Vprašanje, kako bodo sistemi visokošolskega izobraževanja sposobni zaznati te spremembe, ostaja v tem trenutku odprto.

\section{$810 \quad$ Prihodnji izzivi}

Za razumevanje dinamike sprememb na trgu dela $v$ času pandemije in po njej je nujno potrebno razumeti prepletenost delovanja posameznih družbenih podsistemov, kot so zdravstvo, izobraževanje ali pa informacijsko-komunikacijska tehnologija. En od modelov, ki v tem kontekstu pojasnjuje kompleksnost odnosov med podsistemi, je holistični model, ki sta ga zasnovala Tuzovic in Kadabayi (2021). V jedru modela je poslovna odločitev o tem, ali se bo delovanje organizacije nadaljevalo, ugasnilo ali prešlo v fazo hibernacije. Na to vpliva več komponent. Prvo komponento predstavljajo javno zdravje, vladne subvencije in regulacije. $S$ tem so povezane odločitve o tem, kateri sektorji lahko delujejo in delovanje katerih je potrebno omejiti. Arbitrarnost vladnih odločitev lahko v našem okolju ponazorimo z odpiranjem in zapiranjem javnih šol. Druga komponenta je povezana z vprašanjem pravil in praks socialnega distanciranja, kar je moč opazovati na individualni (npr. izolacije, karantene), organizacijski (npr. delo od doma, zaprtje šol) ter javni ravni (npr. prepoved javnega zbiranja). Tretja komponenta je povezana s sektorskimi specifikami, ki kažejo na prepletanje tehnologije, spremenjenega obsega povpraševanja ter intenzivnost kontaktov. Pri tem lahko pomislimo na velike razlike med sektorji javnega transporta, izobraževanja in gostinsko-turističnih storitev. Četrta komponenta je povezana z osebnimi sposobnostmi zaposlenih za prilagajanje na opisane spremembe. Med pandemijo je $\mathrm{v}$ ospredje še posebej stopalo vprašanje možnosti (ne) 
uspešnih prilagoditev na delo s pomočjo informacijsko-komunikacijske tehnologije.

Prepletenost vseh štirih opisanih komponent pomembno vpliva na mentalno, psihološko, socialno in finančno blaginjo oziroma (dobro) počutje zaposlenih (Tuzovic in Kadabayi, 2021). Menimo, da so omenjene komponente zelo povezane s spreminjanjem odnosa med pridobljenimi in pričakovanimi kompetencami, predvsem zaradi spremenjenega in oteženega prenosa tihega znanja in vzpostavitve zaupanja med zaposlenimi, pa tudi zaradi drugačnega odnosa med zaposlenimi in strankami. Opisano predstavlja pomemben gradnik profesionalnega opravljanja dela in poklicne profesionalizacije. S tem so povezana naslednja vprašanja, ki bodo v prihodnje pomembno zaznamovala spremembe poklicne organiziranosti, sistemom izobraževanja in razvoja kompetenc:

a. Kako uspešno bo digitalna tehnologija povezana $\mathrm{z}$ osebnimi in organizacijskimi kompetencami, kot so timsko delo, sprejemanje odločitev ali pa sposobnost učenja $\mathrm{v}$ organizaciji?

b. Kako se bo povečal obseg oddaljenega dela in kakšne bodo pojavne oblike digitalizacije poklicev?

c. Kako se bo spremenila odgovornost zaposlenih za doseganje dobrih delovnih rezultatov? V kolikšni meri bomo priča večjemu opolnomočenju zaposlenih?

d. Kako se bo spremenila dinamika nastajanja novih poklicev in obsolentnost obstoječih?

e. Kako bo pandemija vplivala na splošen trend poklicne (de)profesionalizacije in središčnosti poklicne identitete?

f. Kakšna bo vloga izobraževalnih institucij pri zaposlovanju in kariernem razvoju?

Sklenemo torej lahko, da ima pandemija več ključnih implikacij za trg dela in poklicne spremembe. Prvič, poklice deli na nujne in ostale. Drugič, zaposleni se razlikujejo glede na možnosti fizičnega distanciranja. Tretjič, delo velikega števila zaposlenih je bilo podvrženo »digitalni transformaciji«, pri čemer so se nekateri začasno ali (bolj) trajno soočili z oddaljenim delom, drugi pa ne. Glede na opisane spremembe se je kvaliteta opravljanja poklicnih nalog pri nekaterih zaposlenih spremenila, pri drugih pa ne. Vse opisane spremembe vplivajo na načine razvoja kompetenc visokošolskih diplomantov, o čemer bomo govorili v naslednjem poglavju. 


\section{Izzivi visokošolskega izobraževanja, povezani z razvojem kompetenc za trg dela}

\section{Kontekst razvoja visokošolskih kompetenc pred pandemijo}

Okrepljen javni diskurz o vlogi visokega šolstva pri razvoju kompetenc diplomantov se je $\mathrm{v}$ zadnjem obdobju začel z bolonjsko prenovo visokošolskih programov. To je povezano z notranjo diverzifikacijo (nastajanje novih programov) in zunanjo harmonizacijo (tristopenjski študij). Procesa diverzifikacije in harmonizacije sta bila pospremljena $\mathrm{z}$ retoriko potrebe po izboljševanju profesionalne relevantnosti in zaposljivosti diplomantov. Spremembe študijskih programov so se delno umeščale v kontekst širših strokovno-teoretskih razprav o novih sistemih kvalifikacij (Young, 2007), poklicne deprofesionalizacije (Evetts, 2011), demografskih in globalnih izzivov (Pavlin in Svetlik, 2014) ter opozoril o »banalizaciji« visokošolskega sistema zaradi pojava množično prosto dostopnih spletnih tečajev ${ }^{3}$ (Steffens, 2015). Snovalci politik so od bolonjske reforme dalje procese, povezane s tendenco zaposljivosti diplomantov, sodelovanja med univerzo in gospodarstvom ter razvojem množično prosto dostopnih spletnih teča-

812 jev, opisali kot »modernizacijo« visokošolskega prostora (Pavlin, 2014), pa čeprav so že desetletja prej prihajala opozorila, da bodo procesi, ki so jih snovalci politik videli kot »moderne«, lahko trivializirali utrjene akademske discipline (Becher, 1989), poslabšali odnos med raziskovanjem in poučevanjem (Elton, 1986) ter "proletarizirali" in hibridizirali akademsko profesijo (Henkel, 2007). S tako imenovano modernizacijo naj bi se postavile pod vprašaj nekatere temeljne družbene funkcije visokošolskih sistemov (Teichler, 2011: 403): poglobljeno razumevanje temeljnih akademskih teorij, metod in domen znanja; prispevanje $h$ kulturnemu in osebnemu razvoju; priprava študentov na svet dela, $z$ namenom, da bi se presegalo utrjene organizacijske prakse. V obdobju bolonjske prenove visokošolskih programov se nismo mogli znebiti občutka, da so se deležniki visokošolskih prostorov razdelili na dva pola. Prvi so videli razvoj v usmerjenosti programov na trg dela, kar je povezano z bolj praktično zasnovanostjo visokošolskih programov, drugi pa so razvoj videli $v$ avtonomiji univerze in ohranjanju klasičnih načinov učenja in poučevanja. Prva pot naj bi pripomogla k razvoju poklicno specifičnih kompetenc, druga pa generičnih.

Seveda pa, kot smo omenili v uvodu članka, visoko šolstvo ni edini sistem, ki vpliva na razvoj kompetenc diplomantov, temveč so z njim povezane individualne in demografske značilnosti študentov, relevantne delovne izkušnje, pretekla zgodovina izobraževanja, zaposlitvena zgodovina ter prakse

\footnotetext{
3 Angl. Massive Online Open Course.
} 
izvajanja poklicnih nalog v delodajalskih organizacijah (Allen et al., 2011). Kljub temu se je vprašanje razvoja kompetenc v visokošolskem sistemu pogosto reduciralo na povečevanje obsega praktičnega dela pri delodajalcih, vpeljevanje problemsko zasnovanega učenja v visokošolski kurikulum in različne ostale oblike sodelovanja univerze s potencialnimi delodajalci.

Zgornja razprava jasno kaže, da so imeli deležniki visokošolskih sistemov v zvezi s strateškimi vprašanji o razvoju kompetenc za trg dela že pred pandemijo nejasne predstave in deljena mnenja. $V$ takih razmerah je problematika mladih diplomantov pri iskanju prvih zaposlitev predstavljala enega osrednjih izzivov razvoja politik na področju trga dela in izobraževanja. V tem trenutku se zdi, da je čas pandemije ta strateška vprašanja za nekaj časa potisnil v ozadje.

\section{Aktualni izzivi visokošolskega izobraževanja v času pandemije}

Visokošolski sistemi so med pandemijo morali svojo energijo nameniti v napore prilagajanj kontinuiranega izvajanja programov, procesom odpiranj in ponovnih zapiranj prostorov ter upoštevanju epidemioloških pravil $\mathrm{v}$ pedagoškem procesu (Schleicher, 2020). Ključne aktivnosti, ki so povezane z odnosom med i) varnim učnim okoljem in fizično bližino ter ii) razvojem kompetenc, opisujem v nadaljevanju.

\section{Selitev pedagoškega procesa na splet}

Ena hipnih in najbolj opaznih reakcij visokega šolstva na pandemijo je bila selitev pedagoškega procesa na splet. Pred pandemijo več kot 70 odstotkov akademikov v evropskem prostoru ni nikoli poučevalo prek spleta; v času pandemije jih skoraj 90 odstotkov razmišlja o poučevanju prek spleta tudi po pandemiji (EUA $\left.{ }^{4}, 2020: 3-4\right)$. Sklepamo torej, da je pandemija povzročila trajnejšo spremembo pristopa k poučevanju - nakljub vsem izzivom, ki ga ta prinaša. Prve izkušnje tako obsežnega izvajanja pedagoškega procesa $\mathrm{v}$ visokem šolstvu kažejo, da učenje na daljavo sicer prinaša nekaj prednosti, kot so zmanjševanje stroškov transporta in bivanja, prihranek pri času, kar posledično pomeni več časa za druge aktivnosti, ali pa recimo enostavnejšo izvedbo gostujočih predavanj. Vendar pa sta drugi in tretji val pandemije privedla do močnega zavedanja, da prenos informacij prek Zooma in Microsoft Teamsa pogosto močno okrni bistvo učnega procesa. Predavatelji in študentje so se začeli zavedati, da je kvaliteten učni proces povezan $\mathrm{z}$ "mentalnim učnim prostorom« ter ponotranjanjem tihega znanja (Nonaka in Takeuchi, 1995). Slednje je močno prepleteno tako s čustvenim

\footnotetext{
4 Kratica za Evropsko univerzitetno združenje (European University Association).
} 
doživljanjem učne situacije in situacijskimi prvinami učenja, kot so opazovanje, posnemanje in podobno.

"Univerzitetni hodniki, kavarne, menze, študentski klubi, travniki, študentski domovi in ostali prostori, kjer se združujejo študentje in profesorji, so pri razvoju kompetenc sestavni del procesa visokošolskega izobraževanja: to, kar se dogaja po predavanju, je včasih še boljpomembno kot ... med samim predavanjem." (Pavlin, 2020: 269).

Rezultat učenja je nepremostljivo povezan z mentalno koncepcijo prostora, ki je osebni in kulturni konstrukt. Prostor pa zaznavamo s čutili (vidom, sluhom, dotikom), imaginacijo in jezikom (Tversky, 2003: 66).

\section{Učenje in preverjanje znanja}

Drugi izziv visokošolskega izobraževanja v času pandemije je povezan $s$ težavami pri preverjanju znanja in izvajanju izpitov na daljavo (OECD, 2020). Gre za zelo pomemben element razvoja kompetenc, ki (naj) bi mu v prihodnje visokošolske institucije morale namenjati večjo pozornost (Allen

814 et al., 2011). Selitev preverjanja znanja na oddaljene dostope prinaša številne težave glede plagiaritorstva in akademske (ne)poštenosti, ocenjevanja praktičnega znanja in spretnosti, zagotavljanja enakih možnosti pri pisanju zaradi različnega socio-ekonomskega statusa in tveganj zaradi tehničnih težav (npr. prekinitev interneta). OECD (2020) je sicer v zvezi s tem identificiral nekaj izhodnih taktik, kot so odpoved ali preložitev preverjanja znanja ter spreminjanje pogojev izvedbe, kot je ustno spraševanje, "pristop odprte knjige«, projektno delo in podobno, vendar pa se ti principi ne približujejo, ampak oddaljujejo od ciljev razvoja kompetenc, kot so bile opredeljene v izvedbenih programih.

\section{Mednarodna mobilnost}

Tretji ključni izziv visokega šolstva med pandemijo je povezan z upadom mednarodne mobilnosti. Le-ta je bila $\mathrm{v}$ času bolonjske reforme prepoznana kot en ključnih dejavnikov pri razvoju generičnih in medkulturnih kompetenc, saj je od študentov zahtevala socializacijo in inkulturacijo v drugačna institucionalna okolja. Nekatere prvine teh procesov so namreč sorodne tudi tistim pri prehajanju iz izobraževanja na (mednarodni) trg dela. Že leta 2020 se je število mednarodnih izmenjav več kot prepolovilo, študentje pa so se znašli v velikem stresu zaradi pravnih zagat glede izteka viz ter težav, povezanih s financiranjem in dvojno socialno izolacijo: od novo nastajajočih socialnih mrež v gostujoči državi in od domačega okolja (EUA, 2020). 


\section{Omejitve v raziskovalni dejavnosti in pridobivanje relevantnih delounih izkušenj}

Četrti izziv je povezan z omejitvami v raziskovalni dejavnosti, izvajanju delovne prakse kot tudi ostalih oblikah sodelovanja med univerzo in gospodarstvom. Slednje vključuje omejitve mobilnosti študentov in akademikov v svetu dela, vseživljenjskem učenju, spodbujanju podjetništva itd. Poleg tega je čas pandemije močno otežil pridobivanje relevantnih delovnih izkušenj, ki glede na mednarodne raziskave predstavljajo enega ključnih procesov razvoja kompetenc (npr. Allen et al., 2011). Zmanjšan obseg pridobivanja relevantnih delovnih izkušenj med drugim pomeni tudi upad prihodkov študentskega dela in v nekaterih primerih potrebo po vrniti k staršem, kar na socialno situacijo in psihološko stanje študentov večinoma vpliva izrazito negativno.

Predstavljeni izzivi utegnejo v prihajajočem obdobju pomembno spremeniti relativno vlogo, ki jo imajo visokošolski sistemi pri razvoju kompetenc. Zavedajoč se vseh omejitev in izzivov, ki jih (post)pandemično obdobje prinaša v visokošolski učni sistem, se razvojne usmeritve utegnejo znova spogledovati z razvojem generičnih kompetenc in prenosa teoretičnega znanja na eni strani in ponovne selitve pridobivanja praktičnega znanja nazaj v delodajalske organizacije na drugi. Po mnenju nekaterih akademikov in kritikov bolonjske reforme taka rešitev niti ne bi bila nujno slaba.

\section{Razvoj kompetenc za profesionalno delo v času pandemije}

\section{Dosedanji napori pri razumevanju kompetenc za profesionalno delo}

V mednarodnem prostoru so bili predstavljeni različni pogledi razumevanja kompetenc. Kompetence lahko opredelimo kot znanje o uporabi znanja ter s prepletanjem štirih vrst znanja: »vedeti KAJ « (dejstva), »vedeti ZAKAJ « (vzrok in posledica), »vedeti KAKO« (sposobnost nekaj narediti) in »vedeti KDO«(vzpostavljanje stikov z ljudmi) (Svetlik in Pavlin, 2004). V kontekstu povezovanja izobraževanja in zaposlovanja se pogosto polemizira glede opredelitev kompetenc DeSeCo, kot so

"sposobnosti soočanja z zahtevami ali uspešnega izvajanja nalog, kar vključuje kognitivne in nekognitivne dimenzije", pri čemer "zunanje zahteve, individualne zmožnosti, predispozicije in kontekst predstavljajo kompleksno naravo kompetenc [...] zavedajoč se, da kompetence pridobivamo vse življenje in se jih učimo $v$ različnih institucijah in na različne načine». (OECD 2002: 8, 9) 
Ta definicijska izhodišča gravitirajo k (zdaj že) klišejski trditvi, da »učenje na pamet nima pravega pomena, če tega ne znamo uporabiti v praksi«. Ta trditev je povezana $z$ različnimi pogledi na učenje ne glede na to, ali se pojavlja v sistemih izobraževanja ali v svetu dela. En od pristopov, ki opisuje to problematiko, je tudi teorija predpostavljanja in utemeljevanja ter koncept učenja enojne in dvojne zanke (Agryris, 2004). Pristop razlikuje med enostavnimi oblikami učenja ter bolj kompleksnimi, pri katerih moramo problem in učni kontekst najprej znati pravilno identificirati. Menimo, da to zahteva participacijo v realni (pogosto fizični) situaciji. Le tista učna izkušnja, ki temelji na taki situaciji, namreč sproža globje "pritikline« učenja, kot so ljubezen, skrb, zaupanje, kreativni kaos in občutek za avtonomijo in odgovornost. Omejitev učenja na digitalni prostor te elemente pogosto omeji.

Dve izmed največjih mednarodnih raziskav o zaposljivosti visokošolskih diplomantov v zadnjem obdobju, REFLEX ${ }^{5}$ in $\mathrm{HEGESCO}^{6}$, sta pokazali, da trg dela od diplomantov pričakuje celo vrsto generičnih kompetenc (Pavlin in Svetlik, 2011; Allen in van der Velden, 2011): profesionalne kompetence nikakor niso povezane le z neposrednim izvajanjem poklicnih nalog, temveč temeljijo na sposobnosti analitičnega razmišljanja, prepoznavanja različnih vzorcev delovanja delovnih procesov in s tem povezano sposobnostjo 816 povezovanja abstraktnih in konkretnih idej. To vključuje tako delo s sodelavci in strankami kot tudi aktivacijo ostalih skupin kompetenc. Med temi velja najprej omeniti funkcionalno fleksibilnost. To je skupina kompetenc, ki je povezana s spreminjanjem poklicnega in organizacijskega okolja, tehnologijo in inovacijami. Zaradi tega pogosto ni dovolj, da so diplomanti dobri samo na svojem (disciplinarnem) področju, temveč potrebujejo znanje in kompetence tudi na t.i. komplementarnih področjih. Inženirji, na primer, morajo poznati osnove trženja, tržniki pa morajo poznati tehnične karakteristike izdelkov in storitev, ki jih prodajajo. Opisana dialektika torej zahteva sposobnost hitrega osvajanja novega znanja, pa tudi pogajalske sposobnosti, s katerimi zaposleni zamejujejo in »izpogajajo« svoje področje delovanja in spreminjanje delovnih nalog. Kot tretjo skupino generičnih kompetenc, ki jo navajata prej omenjeni raziskavi, velja omeniti inovativnost in upravljanje znanja. Visokošolski diplomanti naj bi bili sposobni reševati različne probleme in iskati rešitve, vezane na izdelke, storitve in delovne procese. $S$ tem so povezane kompetence, kot so obvladovanje informacijsko komunikacijske tehnologije, vodenje argumentirane razprave s sodelavci in strankami o novih pristopih in idejah ter sposobnost sprejemanja drugačnih pogledov, rešitev in stališč. Na kratko, od diplomantov se ne pričakuje le, da so pri svojem delu inovativni, temveč da so se sposobni vključevati v

\footnotetext{
5 Kratica za "Fleksibilen profesionalec $v$ družbi znanja«.

6 Kratica za »Visoko šolstvo kot generator strateških kompetenc".
} 
inovativno delovno okolje in ga ustvarjati. To je neposredno povezano s komunikacijskimi in medkulturnimi kompetencami kot tudi z vztrajnostjo realizirati določen proces od ideje do zaključka. Četrto skupino generičnih kompetenc je konzorcij opisal kot mobilizacijo človeških virov. Gre za izrazito heterogeno skupino kompetenc, kot so sposobnost koordinacije aktivnosti in delo v timu, sposobnost dela pod stresom, učinkovita poraba časa in vodenje drugih. Večinoma gre za tiste kompetence, ki jih visokošolski diplomanti v prehodu na trg dela najbolj potrebujejo.

V zadnjih dveh desetletjih so se pojavile tudi številne ostale, bolj ali manj empirično podprte konceptualizacije seznamov kompetenc, ki naj bi jih visokošolski sistem razvijal. Ena od teh je recimo konceptualizacija Hanusheka in Woessmanna (2007: 20), ki poudarja kritično razmišljanje, reševanje kompleksnih multidisciplinarnih in odprtih problemov, kreativno in podjetniško razmišljanje, komuniciranje in sodelovanje $\mathrm{v}$ globalnem svetu ter inovativno uporabo znanja pri kreiranju storitev, procesov in produktov. Pri identifikaciji kompetenc seveda niso pomembna le njihova poimenovanja, temveč ustrezno metodološko podprti pristopi. Mnenje avtorja je, da določena tipologija kompetenc pogosto predstavlja le izoliran pogled na vključevanje posameznika $\mathrm{v}$ določen delovni ali izobraževalni proces. Posameznik se $\mathrm{v}$ procesu izobraževanja in dela srečuje $s$ kompleksnim sistemom lastnih navad, osebnostnih lastnosti, vrednot in motivacijskih dejavnikov (Spencer in Spencer, 1993: 9-10). Kompetence tako lahko opišemo s prvinami tihega znanja, ki jih je z obstoječimi metodološkimi pristopi zaenkrat še težko »uloviti«. Kako široko in kompleksno je lahko v resnici področje proučevanja razvoja kompetenc $\mathrm{v}$ podjetjih in izobraževalnih institucijah, lahko med drugim sklepamo iz Oxfordovih zbornikov Pozitivističnih organizacijskih temeljev (Spreitzer in Cameron, 2011) ali pa Pozitivistične psihologije (Snyder et al., 2021). Poglavja v teh zbornikih opisujejo individualne značilnosti (npr. delovna predanost, proaktivnost, kreativnost, radovednost, socialna motiviranost, samoučinkovitost, samoodločenost ...), emocije (npr. pozitivna energija in čustva, čustvena inteligenca, strast, mentalno zdravje, navezanost ...), kreposti in moralne odlike (sposobnost odpuščanja, skromnost, sočutje, pogum, pravičnost, identiteta, zadovoljstvo, optimizem, upanje, empatija, ljubezen ...), odnose $z$ drugimi (koordinacija odnosov, recipročnost, intimnost, zaupanje, humor, psihološka varnost ...) in prakse upravljanja s človeškimi viri (razvoj kariere, socializacija, komunikacija, sposobnost pogajanj, reševanje konfliktov ...).

Namen zapisanega ni relativizirati ali zmanjšati vrednost dosedanjih naporov pri vpeljevanju »kompetenčnega pristopa« $\mathrm{v}$ polje izobraževanja in svet dela. V tekstu smo želeli poudariti potrebo po večji integraciji različnih pogledov in pristopov, ki so potrebni za "uporaben « razvojni model kompetenc visokošolskih diplomantov - še posebno v prehodu na trg dela. $\mathrm{V}$ 
naslednjem poglavju bomo predstavili nekaj razmišljanj, povezanih s tem, in jih poskušali "preslikati« v čas pandemije. Na tej podlagi bomo kasneje predstavili nekaj razvojnih scenarijev razvoja kompetenc v visokošolskem izobraževanju.

\section{Kaj nas v zvezi z razvojem profesionalnih kompetenc $v$ času pandemije najbolj zanima?}

S proučevanjem kompetenc visokošolskih diplomantov se je v mednarodnem prostoru na različne načine ukvarjalo več mednarodnih projektov in raziskav, med katerimi smo posebej omenili raziskavi REFLEX in HEGESCO. Ti med seboj povezani raziskavi sta na podlagi anketiranja več kot 100.000 diplomantov iz 17 evropskih držav pet let po koncu študija začrtali nekaj temeljnih idej o tem, kako naj visoko šolstvo kot tudi delodajalci razvijajo kompetence in kaj naj se na tem področju posebej proučuje (Allen et al., 2011; Pavlin, 2015). Preslikav poudarkov teh zaključkov na čas pandemije se raziskovalci zaenkrat še niso lotili, zato v nadaljevanju ponujamo nekaj konceptualnih izhodišč.

- Različne generične kompetence se razvijajo različno. Skupinske naloge, recimo, krepijo predvsem timsko delo in sposobnost dela pod pritiskom. Raziskovalni projekti imajo poleg razvoja profesionalnih kompetenc pomemben vpliv na učinkovito porabo časa. Učenje za najvišje ocene vpliva na strokovnost na svojem področju in še posebej na učinkovito porabo časa. Zato je uniformna priporočila o razvoju kompetenc treba jemati s previdnostjo. Glede na to bi bile raziskave, povezane z vplivom, ki ga ima pri razvoju generičnih kompetenc redukcija prostorov visokošolskega izobraževanja (predavalnice, laboratoriji, praktično delo itd.) na virtualni prostor, nujno potrebne - še posebej premislek, na kakšen način in v katerih premostitvenih obdobjih bi zaradi fizične izolacije lahko študentje kompenzirali manko razvoja generičnih kompetenc.

- Bolj ko je program zahteven, višja je stopnja doseženih kompetenc, še posebej strokovnosti na svojem področju. Kako je selitev visokošolskega pedagoškega procesa v virtualni prostor vplivala na zahtevnost študija in samo opravljanje izpitov (glej prejšnji razdelek), je v tem trenutku malo znano. Sklepamo lahko, da se je napor, ki je bil v času pred pandemijo potreben za ponotranjanje učne snovi, usmerjen drugam: v ohranjanje koncentracije, samodisciplino ali pa za samo vživljanje v simulacije učnih situacij. Špekulirali bi lahko naprej. Visokošolske institucije, pa tudi delodajalci, pri katerih se opravlja delovna praksa, bi morali vedeti, v kakšni meri učenje na daljavo »izsesava« študentom energijo, jih morda celo uspešno uči osvajanja kompetenc izven učnega načrta, vendar pa povzroča manko kompetenc, ki so zapisane v učnem načrtu. 
- Raziskavi REFLEX in HEGESCO sta jasno pokazali, da relevantne delovne izkušnje v času študija na kompetence in kariere diplomantov bistveno bolj vplivajo kot delovne izkušnje, ki niso relevantne. Zagotavljanje kvalitete študijskih praks je pomenilo velik izziv že v času pred pandemijo, med pandemijo pa so se te oblike pridobivanja kompetenc v mnogih programih (preveč) prilagodile situaciji. Pri tem sklepamo, da se kvaliteta ni povečala. Čas pandemije je $\mathrm{v}$ nekaterih programih opozoril na potrebo po vnovičnem premisleku o smiselnosti (re)integracije praktičnih oblik učenja $v$ študijski proces. Vprašanja so na podoben način povezana z nadaljnjim razvojem mednarodne mobilnosti.

- Na razvoj kompetenc poleg študija pomembno vplivajo delovne in organizacijske izkušnje $\mathrm{v}$ prehodu diplomantov na trg dela. $\mathrm{V}$ tem smislu prve zaposlitve nadgrajujejo in dopolnjujejo razvoj generičnih kompetenc, ki se je pri študentih začel že v času izobraževanja. Na sposobnost dela pod pritiskom, na primer, pomembno vpliva konkurenčno organizacijsko okolje. Usmerjenost organizacije v inovacije in avtonomno delo dopolnjuje širok spekter generičnih kompetenc, ki jih je študent začel razvijati času študija. Čas pandemije je pokazal na potrebo po boljšem razumevanju komplementarnosti razvoja kompetenc v dveh sistemsko ločenih okoljih.

Visokošolske institucije bodo morale $\mathrm{v}$ prihodnje razumeti potrebo po ustreznem kombiniranju različnih načinov učenja ter dopolnjevanju poklicno specifične kompetence $z$ generičnimi in obratno. Bolj kot kdaj koli prej je v času pandemije postalo jasno, da bi moral biti razvoj profesionalnih in generičnih kompetenc nujno utemeljen na empiričnih podatkih in disciplinarno specifičnih razvojnih modelih.

\section{Razmislek o razvoju profesionalnih kompetenc v visokem šolstvu $v$ času pandemije in po njej}

Glede na razpravo v tem poglavju sklepamo, da bodo nekatere spremembe, ki jih je pandemija prinesla $\mathrm{v}$ dinamiko razvoja profesionalnih kompetenc, trajne narave. Večina sprememb je povezana $z$ delom akademske profesije. Ta je $\mathrm{v}$ zadnjem letu začutila spremembe $\mathrm{v}$ raznolikosti, pomenu in smislu ključnih delovnih procesov, možnostih spremljanja povratnih reakcij študentov, avtonomiji in številnih ostalih dimenzijah dela (Kulikowski et al., 2021). Nadaljnja hitrost akademskega dela bo v odnosu do pandemije odvisna od »epidemioloških motenj« v logiki pridobivanja praktičnega znanja, preferenc mladih do izbire visokošolskih programov, novih taktik mednarodne mobilnosti ter praks zaposlovanja. V nadaljevanju opisujemo nekaj (po našem mnenju) najbolj verjetnih scenarijev sprememb dela akademikov in visokošolskih sistemov, ki bodo pomembno vplivali na razvoj kompetenc. 


\section{"Digitalizacija« visokega šolstva}

Čeprav so po zadnjem valu pandemije deležniki visokošolskih sistemov vedno bolj kritični do nadaljnje digitalizacije visokošolskega kurikula, v primeru nadaljnjega poteka pandemije priznavajo, da ta čas razne različice digitalne izvedbe ostajajo zelo verjetna razvojna nuja. Po teh scenarijih naj bi »nov visokošolski kurikul« temeljil na inovativnih oblikah ocenjevanja, povezovanja digitalne pismenosti s profesionalnimi kompetencami, povezovanja pedagoškega procesa s socialnimi omrežji, povečevanju tehničnih kapacitet in varnosti interneta, razvoju digitalnih podpornih portalov in storitev, zahtevah po snemanju predavanj ter zagotavljanju ostalih oblik "upravljanja« različnih medijev in podobno. Webb in drugi (2021) na primer skozi koncepte, kot so »digitalna univerza«, virtualno učenje ali tehnološko podprte oblike učenja, opozarjajo na potrebo uvajanja novih predmetov, povezanih z digitalnimi vsebinami, kot so analiza podatkov, programiranje, digitalni marketing in upravljanje - te vsebine naj bi bile pomembne tako za akademske učitelje kot študente.

\section{Prilagajanje trgu dela}

Drugi scenarij temelji na domnevi, da se bo s pandemijo vpliv trga dela na visoko šolstvo pospešeno krepil. Prvič, mladi naj bi se vedno bolj odločali za vpis na tiste programe, ki se skladajo s (kratkoročnimi) potrebami delodajalcev ali pa s splošnimi predstavami o tem, kaj delodajalci potrebujejo. Ob negotovosti, ki jo je pandemija sicer vnesla na trg dela, ter odsotnosti zanesljivih statičnih podatkov o prehodu mladih na trg dela lahko prihaja do občutnih razlik med percepcijo in realno situacijo. Vpis na nekatere visokošolske institucije lahko tako postane predmet manipuliranja o potrebah na trgu dela, dejanske krize zaposlovanja ali pa kombinacije obojega. Drugič, turbulence na trgu dela naj bi po tem scenariju okrepile splošno predstavo, da morajo biti obstoječi visokošolski programi bolj praktično naravnani - imeti več praktičnih predmetov pred splošnimi in temeljiti na aktivnejših učnih metodah. Pandemija s pravili medsebojne razdalje te učne principe sicer omejuje.

\section{Radikalnejše spremembe}

Retorika na kompetencah zasnovanega pristopa k učenju postavlja na vseh področjih izobraževanja učence in študente v center učne aktivnosti. To pomeni, da bi učenje moralo temeljiti na predhodno osvojenem znanju, da bi med učno snovjo in različnimi predmeti morale obstajati povezave ter da bi predavanja morala temeljiti na integraciji praktičnega učenja in dela. 
Te ideje so povezane z radikalnejšimi spremembami in idejami (visoko) šolskega izobraževanja. Temeljijo na obsežnem združevanju formalnega in neformalnega izobraževanja in podeljevanju kreditov za relevantno pridobljene delovne izkušnje. Tak sistem bi povezoval učenje $\mathrm{v}$ predavalnicah $\mathrm{z}$ učenjem in poučevanjem v lokalnih okoljih, pri čemer naj bi se študentje učili s pomočjo ekspertov in hkrati tudi mestoma prevzemali njihove vloge. Pandemija naj bi bila čas za refleksijo in razmislek o možnosti vpeljevanja nekaterih tradicionalnih razvojnih idej (Pavlin et al., 2016; Sawyer, 2019): prilagajanje pedagoškega procesa različnim učnim tipom, gradualnosti sistemov izobraževanja, $v$ katerem učenci napredujejo glede na realno znanje in ne glede na starostne skupine, intenzivno vključevanje podjetij, muzejev, javnih knjižnic in profesionalnih združenj ter utemeljevanje učnih procesov na različnih specialnostih pedagogov (specialisti, generalisti, eksperti ...).

\section{Posel kot običajno (business as usual)}

Četrti scenarij temelji predvsem na predpostavki, da se bo pandemija v kratkem končala. Po tem scenariju naj bi ostalo pandemično obdobje predvsem neprijeten spomin. Študentje naj bi ob upoštevanju epidemioloških ukrepov, ki bodo začeli postopno kopneti, spet napolnili predavalnice. Visoko šolstvo naj bi se vrnilo na točko reševanja izzivov pred pandemijo: zagotavljanja profesionalne relevantnosti študijskih programov, povezovanja raziskovanja in učenja, povečevanja mednarodne mobilnosti, prilagajanja financiranja skladno z aspiracijami po "zagotavljanju kvalitete«, sodelovanja $\mathrm{z}$ gospodarstvom ...

\section{Hibridni model}

Hibridni model je $\mathrm{v}$ tem trenutku najbolj verjeten. Vključuje različne prvine prej opisanih scenarijev. Pri tem je mogoče upati, da si bo v intervalih popuščanj pandemije akademska skupnost vzela čas za refleksijo obdobja zaprtja univerz ter pripravila načrte »delnih kompenzacij« fizične izolacije.

V zaključku tega dela naj ponovimo misel, da bo izbor scenarijev odvisen od poteka pandemije. Kaj torej lahko med čakanjem na razplet epidemiološke situacije v teh negotovih časih zapišemo v sklep?

\section{Sklep}

Pričakovati je, da vsaj v kratkoročnem obdobju visokošolske institucije ne bodo sposobne izvesti korenitih strateških razmislekov, vezanih na pandemijo. Obremenjene bodo z iskanjem kratkoročnih rešitev prilagajanja izvajanja pedagoškega procesa. Pričakovati je dinamiko med i) poskusi vrnitve 
k »(pred)epidemiološkim" oblikam izvedbe pedagoškega procesa ter ii) oddaljenimi oblikami poučevanja. To je povezano s postopno potrebo po inovativnih pristopih ocenjevanja, povečanju obsega individualnih konzultacij, izkoristku oddaljenega dostopa za vključevanje tistih akterjev, ki lahko doprinesejo $\mathrm{k}$ večji profesionalni relevantnosti visokošolskega izobraževanja, delovanju socialnih omrežij in podobno. Vendar pa, kot smo opozorili v članku, mnoge oddaljene oblike občutno omejujejo prenos tihega znanja oziroma socializacijskih komponent učenja. Zato se smiselna rešitev pri pripravi razvojnih scenarijev verjetno ne skriva $v$ pripravi načrtov enovitih izvedb (klasične, digitalne in hibridne), temveč v vzpostavitvi organizacije dela, ki bo v primeru cikličnih nihanj pandemije omogočala enostavna prehajanja in dopolnjevanja med posameznimi povezanimi etapami razvoja kompetenc. Tak pristop bo predstavljal za fakultetno administracijo in akademike zelo velik izziv, vendar po našem mnenju ta hip predstavlja najbolj verjetno možnost. Pri tem je eno ključnih vprašanj, kako naj visokošolski sistem nadoknadi socializacijske elemente učnega procesa, za katere je študent zaradi oddaljenega pristopa prikrajšan.

V članku smo odgovorili na temeljno raziskovalno vprašanje o tem, kakšni so glede na potek pandemije možni scenariji razvoja kompetenc $\mathrm{v}$ 822 visokem šolstvu. Na podlagi pregleda literature in lastnih konceptualnih izhodišč smo prepoznali in razčlenili pet scenarijev: »digitalizacijo « visokega šolstva, intenzivno prilagajanje visokošolskih programov trgu dela, vpeljevanje radikalnih sprememb, nadaljevanje posla kot običajno ter izvajanje hibridnega modela.

Raznoterost razvojnih možnosti nas vrača h klasični dilemi razvoja profesionalnih kompetenc in vprašanja, ali naj sistem razvija predvsem generične ali poklicno specifične kompetence. Med drugim so odgovori povezani z možnimi spremembami načinov poučevanja in obsega vključitve zunanjih "profesionalnih" deležnikov v pedagoški proces ter podeljevanja kreditov za relevantne delovne izkušnje. Pri tem sklepamo, da monolitna rešitev sodelovanja med visokih šolstvom in svetom dela ne bo mogoča in tudi ni smiselna. Scenariji bodo morali upoštevati specifike posameznih visokošolskih disciplin kot tudi "poklicno« naravnanost visokošolskih programov. Vendar pa so mnogi principi zagotavljanja kvalitete visokošolskih programov pri tem enaki za vse discipline. Med temi velja izpostaviti regulacijo zahtevnosti študija ter vpeljavo sistemov spremljanja prehoda diplomantov na trg dela. Pri tem se sprašujemo, v kolikšni meri bo zaradi digitalizacije profesionalnega dela in učenja pandemija vplivala na sposobnost delovanja študentov na trgu dela $v$ daljšem obdobju. Ignoriranje tega vprašanja bo problem razvoja kompetenc le še poglobilo. 


\section{LITERATURA}

Alam, Manzulur (2020): Organisational processes and COVID-19 pandemic: implications for job design, Journal of Accounting \& Organizational Change 16 (4): 599-606.

Allen, Jim, Samo Pavlin in Rolf van der Velden (ur.) (2011): Competencies and early labour market careers of higher education graduates in Europe. Ljubljana: Fakulteta za družbene vede.

Allen, Jim in van der Velden, R. (2011): The Flexible Professional in the Knowledge Society: Required Competences and the Role of Higher Education. V: Jim Allen (ur.) in Rolf van der Velden (ur.), The Flexible Professional in the Knowledge Society - New Challenges for Higher Education. Dordrecht: Springer, 15-54.

Argyris, Chris (2004): Reasons and Rationalizations: the Limits to Organizational Knowledge. Oxford: Oxford University Press.

Becher, Tony (1989): Academic Tribes and Territories: Intellectual Enquiry and the Culture of Disciplines. Buckingham: Open University Press.

Bishop, Peter, Andy Hines, Terry Collins (2007): The current state of scenario development: an overview of techniques, Foresight 9 (1): 5-25.

Dirani, M. Khalil, Mehrangiz Abadi, Amin Alizadeh, Bhagyashree Barhate, Rosemary Capuchino Garza, Noeline Gunasekara, Ghassan Ibrahim in Zachery Majzun (2020): Leadership competencies and the essential role of human resource development in times of crisis: a response to Covid-19 pandemic, Human Resource Development International 23 (4): 380-394.

Elton, Lewis (1986): Research and teaching: symbiosis or conflict Lewis. Higher Education, 15 (3-4): 299-304.

Evetts, Julia (2011): A new professionalism? Changes and opportunities, Current Sociology, 59 (4): 406-422.

Gonzales, Julia (ur.) in Rober Wagenaar (ur.) (2003): Tuning Educational Structures in Europe. Final Report. Phase One. University of Deusto in University of Groningen. Bilbao: Universidad de Deusto.

Hanushek, A. Eric in Ludger Woessmann (2007): The role of school imporovement in development, working paper 12832, National Bureau of Economic Research, Massachusetts, January. Dostopno prek http://www.nber.org/papers/w12832. pdf, 31. 5. 2021.

Henkel, Mary (2007): Shifting Boundaries and the Academic Profession. V: Maurice Kogan (ur.) in Urlich Teichler (ur.), Key Challenges to the Academic Profession. Paris and Kassel: UNESCO Forum on Higher Education, 191-204.

Kien, Le in My Nguyen (2021): The psychological consequences of COVID-19 lockdowns, International Review of Applied Economics 35 (2): 147-163.

Kulikowski, Konrad, Sylwia Przytuła in Łukasz Sułkowski (2021): E-learning? Never again! On the unintended consequences of COVID-19 forced e-learning on academic teacher motivational job characteristics. Higher Education Quarterly: $1-16$.

Messenger, C. Jon in Lutz Gschwind (2016): Three generations of Telework: New ICTs and the (R)evolution from Home Office to Virtual Office. New Technology, Work and Employment 31 (3): 195-208. 
Mlinar, Zdravko (2003): Teledelo in prostorsko-časovna organizacija bivalnega okolja, Teorija in praksa 40 (6): 1012-1039.

Nonaka, Ikujiro in Hirotaka Takeuchi (1995): The Knowledge-Creating Company: How Japanese Companies Create the Dynamics of Innovation. Oxford: Oxford University Press.

Pavlin, Samo (2014): The role of higher education in supporting graduates' early labour market careers, International Journal of Manpower 35 (4): 576-590.

Pavlin, Samo (2015): Kako študij in prve zaposlitvene izkušnje vplivajo na razvoj kompetenc visokošolskih diplomantov? Sodobna pedagogika 66=132 (4): 62-77.

Pavlin, Samo (2020): Izzivi proučevanja zaposljivosti visokošolskih diplomantov v času izobraževanja na daljavo in po njem. V: Ignjatović, Miroljub (ur.), Kanjuo-Mrčela, Aleksandra (ur.), Kuhar, Roman (ur.). Družbene neenakosti in politika: Slovensko sociološko srečanje, Ljubljana, 6.-7. november 2020. 1. natis. Ljubljana: Slovensko sociološko društvo, 267-270.

Pavlin, Samo, Tobias Kesting in Thomas Baaken (2016): An integrative view on higher education and university-business cooperation in the light of academic entrepreneurship. European journal of education 51 (1): 3-9.

Pavlin, Samo in Ivan Svetlik (2011): The World of Work and the Demand for Comptences. V: Jim Allen (ur.), Samo Pavlin (ur.) in Rolf van der Velden (ur.). Competencies and Early Labour Market Careers of Higher Education Graduates in Europe. Ljubljana: Univerza v Ljubljani, Fakulteta za družbene vede 73-106.

Pavlin, Samo in Ivan Svetlik (2014): Employability of higher education graduates in Europe, International Journal of Manpower 35 (4): 418-424.

Pavlin, Samo, Ivan Svetlik in Julia Evetts (2010): Revisiting the Role of Formal and Practical Knowledge from a Sociology of the Professions Perspective: The Case of Slovenia. Current Sociology 58 (1): 94-118.

Powell, N. Gary (2020): Work-family lockdown: implications for a post-pandemic research agenda. Gender in Management: An International Journal 35 (7/8): 639-646.

Steffens, Karl (2015): Competences, Learning Theories and MOOCs: Recent Developments in Lifelong Learning. European Journal of Education 50 (1): 41-59.

Teichler, Urlich (2011): Universities between the Expectations to Generate Professionally Relevant Competences and Academic Freedom: Experiences from Europe. V: Y. Cheng (ur.) in X. Gu (ur.). The Harmoy of Civilisatons and Prosperity for All. Commitments and Responsibilities for a Better World. Select Papers of Beijing Forum 2010. Peking: Peking Universitiy Press, 400-414.

Tuzovic, Sven, in Sertan Kabadayi (2021): The influence of social distancing on employee well-being: a conceptual framework and research agenda, Journal of Service Management 32 (2): 145-160.

Tversky, Barbara (2003): Structures Of Mental Spaces - How People Think About Space, Environment and Behavior 3 (1): 66-80.

Sawyer, R. Keith (2019): Conclusion: The Future of Learning: Grounding Educational Innovation in the Learning Sciences. V: Sawyer. R. Keith (ur.) The Cambridge 
Handbook of The Learning Sciences. Second Edition. New York. Cambridge University Press, 726-746.

Snyder, R. Charles (ur.), Shane J. Lopez (ur.), Lisa M. Edwards (ur.) in Susana C. Marques (ur.) (2021): The Oxford Handbook of Positive Psychology (tretja izdaja). New York. Oxford University Press.

Spencer, M. Lyle in Signe M. Spencer (1993): Competence at Work: Models for Superior Performance. New York: Wiley.

Spreitzer, M. Gretchen in Kim S. Cameron (2011): The Oxford Handbook of Positive Organizational Scholarship. New York. Oxford University Press.

Svetlik, Ivan in Samo Pavlin (2004): Izobraževanje in raziskovanje za družbo znanja. V: Z. Mlinar (ur.). Demokratizacija, profesionalizacija in odpiranje v svet. Teorija in praksa 41 (1-2): 199-211.

Torraco, Richard J. (2016): Writing Integrative Literature Reviews: Using the Past and Present to Explore the Future, Human Resource Development Review 15 (4): 404-428.

Webb, Aleksandra, Ronald Willian McQuaid, C. William R. Webster (2021): Moving learning online and the COVID-19 pandemic: a university response, World Journal of Science, Technology and Sustainable Development 18 (1): 1-19.

Young, Michael (2007): Qualifications Frameworks: some conceptual issues, European Journal of Education 42 (4): 445-457.

\section{VIRI}

EUA (2020): BRIEFING European higher education in the Covid-19 crisis. European University Association asbl. Brussels and Geneva. Dostopno prek https://eua. eu/downloads/publications/briefing_european\%20higher\%20education $\% 20$ in\%20the\%20covid-19\%20crisis.pdf, 1. 6. 2021.

Eurofound (2021): COVID-19: Implications for employment and working life, COVID-19 series, Publications Office of the European Union, Luxembourg.

ILO-OECD (2020): The impact of the COVID-19 pandemic on jobs and incomes in G20 economies. ILO-OECD paper prepared at the request of G20 Leaders. Saudi Arabia's G20 Presidency 2020. Dostopno prek https://www.ilo.org/wcmsp5/ groups/public/---dgreports/---cabinet/documents/publication/wcms_756331. pdf, 1. 6. 2021.

Mühleck, Kai, Christoph Meng, Stefanie Oelker, Martin Unger, Roberta Lizzi, Sigi Maurer, Ivan Rimac, Hans Rutjes, Katarina Wessling (2020): EUROGRADUATE Pilot Survey - Technical assessment and feasibility of a full rollout. Brussels. European Commission. Dostopno prek https://op.europa.eu/en/publicationdetail/-/publication/8f748637-d079-11ea-adf7-01aa75ed71a1/language-en, 31. 5. 2021.

OECD (2002): Definition and Selection of Competencies (DESECO): Theoretical and Conceptual Foundations. OECD in Statistični urad Švice. Dostopno prek http://www.deseco.admin.ch/bfs/deseco/en/index/02.html, 1. 6. 2021.

OECD (2020): "Remote online exams in higher education during the COVID-19 crisis", OECD Education Policy Perspectives, No. 6, OECD Publishing, Paris. Dostopno prek https://doi.org/10.1787/f53e2177-en, 1. 6. 2021. 
OECD (2021): AdultLearning and COVID-19: How much informal and non-formal learning are workers missing?.OECD. Paris. Dostopno prek https://www.oecd. org/coronavirus/policy-responses/adult-learning-and-covid-19-how-muchinformal-and-non-formal-learning-are-workers-missing-56a96569/, 1. 6. 2021.

Schleicher, Andreas (2020): The impact of COVID-19 on education - Insights from Education at a Glance 2020. OECD Paris. Dostopno prek https://www.oecd. org/education/the-impact-of-covid-19-on-education-insights-education-ata-glance-2020.pdf, 1. 6. 2021. 